\title{
A contemporary look at language origins
}

\author{
Sławomir Wacewicz \\ Center for Language Evolution Studies (CLES) \\ Nicolaus Copernicus University, Toruń, Poland \\ wacewicz@umk.pl
}

\begin{abstract}
Why is language unique? How did language come about? When did this happen? These questions, although quite emblematic of the Western intellectual tradition since its ancient beginnings, so far have not found satisfying answers. Indeed, many still question the very possibility of addressing these basic problems of the origins of language with proper scientific rigor (see e.g. Hauser et al. 2014). However, an emerging consensus is that current research in the field of language evolution is in fact bearing fruit, making it at least possible to judge in an informed manner which of these competing scenarios are far more or less probable. In what follows, I guide the reader through some of this research and some of these scenarios; for more details, I refer the reader to a recent book (Żywiczyński \& Wacewicz 2015), which is the first monograph that presents this developing field of language evolution research to the Polish reader.
\end{abstract}

Keywords: language evolution; evolution of language; protolanguage; language origins; cooperation; evolutionary linguistics; gestural primacy,

Why is language unique? How did language come about? When did this happen? These questions, although quite emblematic of the Western intellectual tradition since its ancient beginnings, so far have not found satisfying answers. Indeed, many still question the very possibility of addressing these basic problems of the origins of language with proper scientific rigor (see e.g. Hauser et al. 2014). However, an emerging consensus is that current research in the field of language evolution is in fact bearing fruit, making it at least possible to judge in an informed manner which of these competing scenarios are far more or less probable. In what follows, I guide the reader through some of this research and some of these scenarios; for more details, I refer the reader to a recent book (Żywiczyński \& Wacewicz 2015), which is the first monograph that presents this developing field of language evolution research to the Polish reader. 


\section{Why is language unique?}

Why is language unique? A traditional answer to this question is based on a system of so-called design features of language, developed in the 1950s and 1960s by the American linguist, Charles Hockett. His lists, depending on the version, enumerate 13 to 16 features (Hockett 1958, 1960; Hockett \& Altmann 1968), most of which could individually be found in different animal communication systems, but the full set of which is present only in language. Hockett's terminology is still broadly used and many of the features have considerable descriptive value, examples being displacement (communicating about entities not currently present in the vicinity, i.e. beyond "here and now") or duality of patterning (first combining individually meaningless phonemes into meaningful morphemes or words, which are then combined on a higher level into larger meaningful units, such as phrases and sentences). However, as I argue elsewhere (Wacewicz \& Żywiczyński 2015b), the Hockettian approach has only limited utility in modern language evolution research. This is because it unduly prioritizes spoken over signed language, and secondly, it fails to capture several characteristics that are quite central to language (see below).

Finally, Hockett's lists focus on superficial similarities: they describe communication as an external, abstract and disembodied product, detached from the producer, and specifically from the producer's cognitive machinery underlying its production. This can be called a "phenetic" approach to communication, by analogy with pheneticism in biological taxonomies, which would lump whales together with fish, which they physically resemble; this approach is not devoid of descriptive value, but is not particularly well suited to capturing phylogenetic continuities ${ }^{15}$. A characteristic example is humans and honey bees ${ }^{16}$ : their communication systems do share, on the surface, a number of "Hockettian" features, but this fact translates into very little useful information about the phylogeny of language, given the cladistic distance between humans and bees. Clearly, from the evolutionary-linguistic perspective, attention should be directed "inwards", to the underlying cognitive capacities that make it possible for organisms to acquire and use language in the first place. Displacement is a good case in point: while nonhuman apes do not seem to communicate about displaced referents, they are very clearly capable of some degree of displaced thought (e.g. Savage-Rumabaugh et al. 1980), thus pointing to the expected evolutionary continuity between ape and human cognitive systems.

A sizeable yet important minority insist that the uniqueness of language is a matter of its combinatorial power, reflected in the rules of morphology and syntax (e.g. Fitch et al. 2005). One particular trait that has received particular

\footnotetext{
${ }^{15}$ Another analogy which I develop in the book in this context, is that of kites and jet planes (Żywiczyński \& Wacewicz 2015: 182).

${ }^{16}$ The famous honeybee dance was first described by Frisch $(1957,1962)$.
} 
interest from this theoretical perspective is recursion. As traditionally defined in linguistics, recursion is the process whereby a syntactic unit is embedded in a syntactic unit of the same type, e.g. the noun phrase "my father's" embedded in the larger nominal phrase "my father's mother" (Pinker 1994). In 2002, Hauser, Chomsky and Fitch (2002) hypothesized that recursion may in fact be the only qualitative difference between human language and animal communication (alongside possible differences of degree rather than type). This extremely seminal Science paper canalized a nontrivial proportion of language evolution research in the succeeding decade, spawning numerous comments on what recursion really is (e.g. Parker 2006), which other cognitive systems are recursively organized (e.g. vision, see Jackendoff \& Pinker 2005), or where else recursion is present in the animal kingdom (e.g. Gentner et al. 2006). Today, we perceive this recursion-only route largely as a dead end, or at the very least as a part that must be integrated into a much more pluralistic approach. Language is clearly an extremely complex phenomenon, and reducing it to its combinatorial dimension is simply not theoretically legitimate (Wacewicz \& Żywiczyński 2015a) ${ }^{17}$.

My own position on the uniqueness of language (Żywiczyński \& Wacewicz 2015, chapter 5) is not in fact a novel one. Actually, it is a near-consensus in language evolution research (see esp. Tomasello 2008), but one that is dramatically underappreciated: language is truly unique in being a cheap but honest, evolutionarily stable signaling system, i.e. a system based on strategies that, once accepted, cannot be outcompeted by rival strategies (Axelrod 1984). According to signaling theory, when studying communication from the vantage point of evolutionary biology (Maynard Smith 1982), the reliability, or honesty of signals, is usually guaranteed by its cost, i.e. the higher the cost, the more reliable the signal. This concerns especially the strategic cost paid by an animal as a kind of insurance that a signal is indeed reliable (Maynard Smith and Harper 2003). The strategic cost is illustrated by the handicap principle (Zahavi 1975); specifically in the case of signaling biological quality, a higher quality individual is able to pay the cost that a lower quality individual is unable to afford, the classic example of which is the peacock's tail. Linguistic communication entails only negligible energetic costs, thus lacking a basic mechanism for telling apart true and false messages. Although this should make language unreliable, people generally communicate cooperatively rather than deceptively ${ }^{18}$.

\footnotetext{
${ }^{17}$ An important footnote to Hauser et al. (2002) and the papers published in its wake is a terminological one: that the key term, Faculty of Language in the narrow sense (FLN) has been functioning in two distinct, incompatible meanings. I have emphasised this point repeatedly (e.g. Wacewicz 2012, Wacewicz \& Żywiczyński 2015a), because-despite the import of the term "FLN"-it has been overlooked by a large majority of commentators.

${ }^{18}$ Cf. Camilla Power (2014: 50): "Signal evolution theory is the main body of theory applied to animal communication. So it is axiomatic that any scientific study of the evolution of language
} 
That this fact about language and its evolution is grossly underappreciated is especially true in linguistics, where the cooperative nature of language is an expected default that is simply taken for granted. This is both an intuitive and a theoretical expectation. Intuitively, we know that (for the most part) people do not lie, so, as a rule, we do not expect to be lied to, nor do we demand detailed and incontrovertible evidence for the truth of every single assertion that our interlocutors make in a conversation. We just trust them. To an extent, this intuition was formalized by Grice as his famous Cooperative Principle (1975). Grice argues that conversation, and largely speaking linguistic communication as such, is a thoroughly cooperative enterprise since is based on informative incompleteness, whereby conversants must resort to inference to properly interpret utterances, or, to use Grice's dictum, conversational implicature. Hence, successful linguistic communication requires that a producer should formulate her contribution in a way that helps a receiver in this inferencing process.

If the cooperative character of language can be considered a trivial "fact of life" from the synchronic perspective, this is not so from the evolutionary point of view. Here, it is an explanatory target, not a given: the cooperative nature of linguistic communication is precisely the crucial qualitative difference that we aim to explain: a "central puzzle" (Fitch 2010: 417).

\section{How did language come about?}

I agree with Michael Arbib (2013: 107): "[t]he short answer ... is <through biological and cultural evolution>. The challenge is to be more specific." One difficulty in being specific is that this question unpacks as a collection of more detailed ones, such as "what were the selection pressures guiding the evolution of a language-ready brain?", "how did biological evolution and cultural evolution interact?", and "what were the stages in the development of the language faculty?" Since each deserves a dedicated paper, if not a book, for the first two I limit myself to simply reporting recent trends. Firstly, most commentators point to social (rather than e.g. ecological) pressures as being responsible for the emergence of a number of characteristically human features, most importantly, big brains and language (see e.g. Pina \& Gontier 2014). The early expression of this trend in thinking about human evolution in general, and evolution of language in particular, was dominated by the problems of manipulation, coalition-making and social dominance, in consonance with the Machiavellian Intelligence Hypothesis (Byrne \& Whiten 1988). This motif was continued by Dunbar, who with his collaborators managed to

adopts this theoretical approach as starting point. To argue that the evolution of language is a special case to which signalling theory does not apply, we have to explain why not, within that theory's terms". 
demonstrate that the size of the primate neocortex is strongly correlated with group size (the Social Brain Hypothesis: 1995, 1996, 2007). This led him to the controversial proposal that language developed as a substitute grooming mechanism that appeared as a consequence of the pressure from the growth of hominin groups (Dunbar 1996; for criticism, see Power 1998 and Bickerton 2003).

Secondly, whereas literature in the 1990s tended to focus on the biological evolution of a genetically determined human language capacity, recent accounts acknowledge to a far greater extent the role of cultural evolution, which could not only have worked "on top" of the genetic basis, once it was brought about by biological evolution, but could have worked together with the latter process in a co-evolutionary feedback loop. Metaphors include language (the external linguistic code) itself as an evolving organism, e.g. a kind of "useful parasite" (see Christiansen 1994), or language as "information technology" (Dor 2014), not unlike lithic technology or food processing technology.

So, what were the stages in the development of language? Firstly, some steps are almost a matter of logical necessity: it is vanishingly improbable that the emergence of a communication system that we would recognize as linguistic could happen in just one step, from no language to full language. Below, I present a model of a possible succession of stages, fully aware of its necessarily speculative character: it is meant as a mere organizing heuristic, admittedly fallible, but still cognitively helpful.

It is important to remember about the hypothetical nature of this "conceptual sketch". The individual features-the prerequisites and components of language-have a status of theoretical constructs singled out analytically, and the relative positions of particular stages reflect this author's own proposal and might not necessarily be a matter of a broad consensus.

\section{BASELINE}

An intuitive view of the origin of language puts the source of that ability in extant primate vocal communication. As was the case for Hockett's features, this is again focusing on surface rather than real similarities: the evolutionary bases of language must be traced back not so much to ape communication, but primarily to ape cognition. Consequently, what I assume here as a baseline, or "point of departure", are the hypothetical cognitive abilities of the last common ancestor of humans and chimpanzees (last common ancestor, LCA), which lived about 6-7 million years ago. The only viable way to inform such an explanatory target is through an approximate reconstruction based on data derived from other primates, and particularly from our closest living relatives, representatives of the genus Pan (chimpanzees and bonobos), with due attention given to the unique evolutionary histories of each species. 


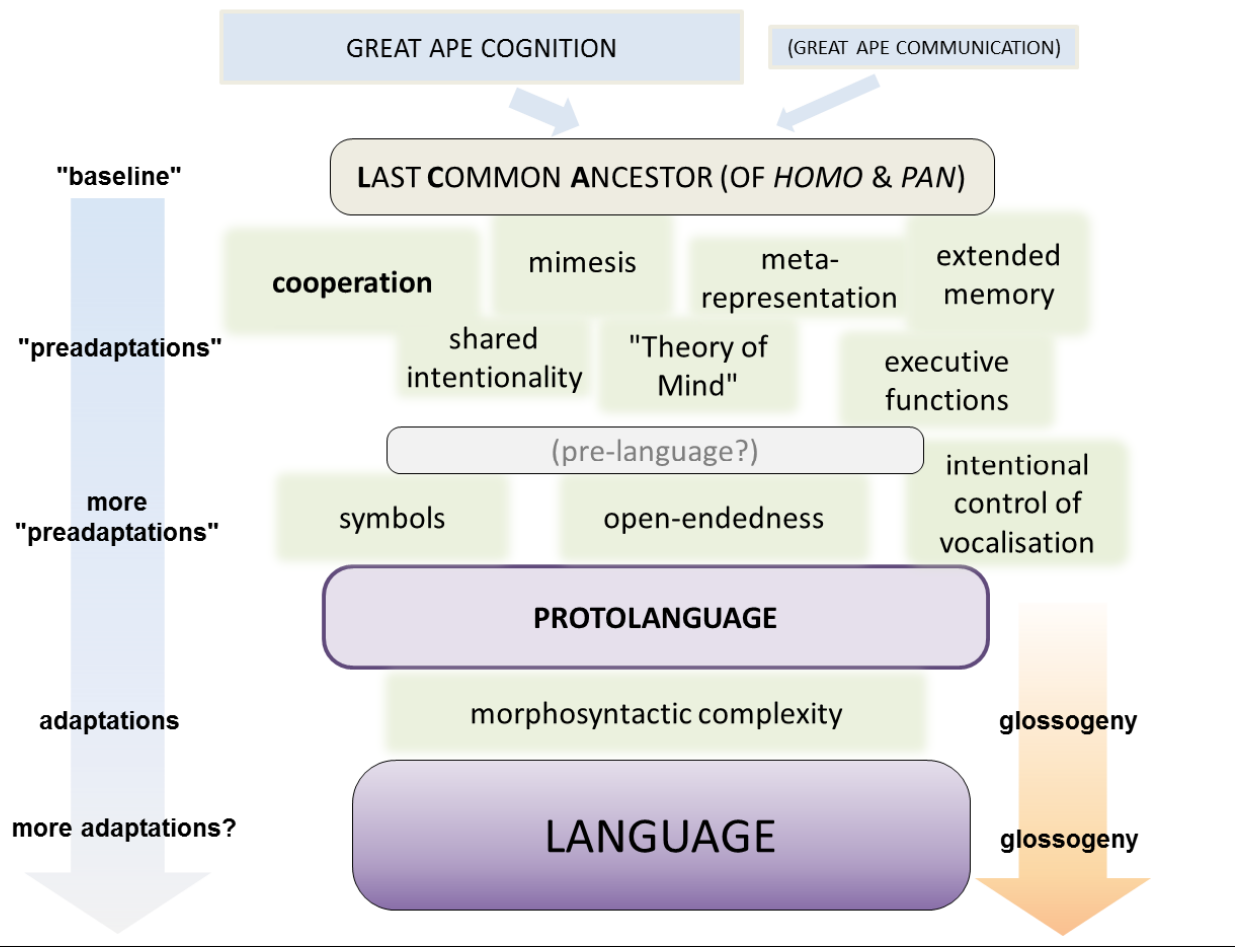

Figure 1. The hypothetical stages of the development of language. The left and right arrows represent the process of biological evolution and cultural evolution, respectively.

\section{PREADAPTATIONS}

The term "preadaptation" should not imply teleology or foresight, since evolution has none. Consequently, preadaptations are not features that emerged "in order to" make language possible; rather, they must have emerged independently on the strength of their own adaptive value in biological evolution. On the other hand, language could only arise after they had been in place, since they provide the indispensable basis and preconditions for its evolutionary emergence.

For reasons explained above, I consider cooperation to be the most essential of the suite of such preadaptations. Others include (Żywiczyński \& Wacewicz 2015, chapter 4):

- mimesis - "the ability to produce conscious, self-initiated, representational acts that are intentional but not linguistic" (Donald 1991: 168); underlying training motor skills (refining through practice), panto- 
mimic communication, imitation leading to cultural invention, and ceremonies and rituals.

- theory of mind (ToM) - the ability to perceive others as autonomous subjects with their own goals and mental states different from our own, and to understand the content of their mental states (in fact, ToM is a convenient umbrella term for a suite of more specific abilities such as reading someone's intentions, goals, etc.).

- enhanced memory - including long-term memory for building and maintaining a mental lexicon of 50 thousand or more items, and working memory for online, real-time combination of those lexical units into phrases and clauses.

\section{PROTOLANGUAGE}

As mentioned above, single-step, catastrophic, scenarios of language origins now seem to be limited to Chomsky and his close collaborators (e.g. Chomsky 2010), and at least partly depend on a peculiar definition of the term "language". Conversely, "[m]ost scholars agree that there must once have been a predecessor of human language, or protolanguage, which did not contain the complex syntactic structures prevalent in modern languages..., but they disagree vehemently over the nature of protolanguage, and over how it developed into modern human language" (Smith 2008: 99). For the consensus part, the term protolanguage comes from Bickerton (1990), who originally used it to denote a system of quasi-linguistic communication consisting of conventional and arbitrary lexical elements, but with no morphosyntax. This term is frequently extended to mean "language minus grammar" (Pinker 1994) or indeed any hypothetical "intermediate" communicative system sharing some, but not all, features of modern language: simpler than language on the one hand, but on the other differing from the systems which we find in present-day monkeys and apes.

As for the controversy part, several principal views on the nature of protolanguage exist (cf. e.g. Fitch 2010: 399-507). Current debates revolve around the questions of its putative modality and structure. The best-known typology of views on protolanguage is that proposed by Fitch, who adheres to the logic of modality and distinguishes:

- the vocal-lexical position - protolanguage is here understood as a lexicon deprived of morphology and syntax; apart from Bickerton's original presentation (1990), Jackendoff's gradualist scenario of syntax growth (1999) as well as a variety of other well-known proposals, such as Dunbar's grooming-gossip hypothesis (1996) or MacNeillage's "content-frame" scenario (2008). 
- the musical position - appeals to the intuitions derived from Darwin (1871) and Jespersen (1922) that the first form of linguistic communication consisted in combinatorially organized songs; the most important modern manifestations of this view are Fitch's "bare phonology" (2010) and Mithen's idea of Hmmmm, i.e. holistic, manipulative, multimodal, musical and mimetic protolanguage (2005)

- the gestural position - traces back protolanguage to gestural communication, as argued by Hewes, (e.g. 1973), Corballis (e.g. 2002) or Arbib (2005), who stress the discontinuity between vocal behaviors of great apes and humans. In a larger sense, multimodal views, which take linguistic communication to be inherently vocal and visual, are subsumed under this rubric (Kendon 2011, McNeill 2012, Sandler 2013).

Another line of opposition in the accounts of protolanguage concerns its structure. The majority view of protolanguage, i.e. combinatorial protolanguage, holds that protolanguage started simple, as a collection of quasi-lexical items, only later gaining rules for combining these units (Bickerton 1990, Jackendoff 1999, Dunbar 1996). Such a position contrasts with the holistic view, first formulated by Wray (1998), which is based on the assumption that protolanguage consisted of complex units with holistic meanings that only later decomposed into the equivalent of modern words (see also Arbib 2005).

The main challenge for any of the above positions is to account for the transition from protolanguage to full language as presently used in human populations. In the case of the vocal-lexical scenarios, the difficulty consists in explaining the emergence of combinatorial principles enriching the protolexicon in morphology and syntax. Proponents of a gestural protolanguage, in addition to development of syntax, have to surmount the problem of the transition to the predominantly vocal modality characteristic of modern language $^{19}$. In a way, the musical accounts face a reverse problem of demonstrating how protolanguage could have gained the type of meaning associated with lexical symbols; for example, in Fitch's model of "bare phonology" the musical structure endows protolanguage with basic combinatorics and thus the main explanatory problem is to demonstrate how such a system came to acquire semantics. Finally, the holistic accounts, such as those by Wray or Arbib, seem to have the most convoluted explanatory pathway, requiring both a plausible account of the decomposition process and then transition to modern syntax.

\footnotetext{
${ }^{19}$ This difficulty is addressed in detail in Żywiczyński \& Wacewicz 2015, Chapter 6.
} 


\section{When did language begin?}

In a sense, this question is the most problematic of all three, because support for a very wide range of dates can be found in the various "language origins" literatures. Until recently, it was relatively common, at least in broad interest publications (e.g. Leakey 1994), to see language origins put at about 50 kya (thousand years ago), most likely a result of Chomsky's influential position (e.g. 2010) together with older interpretations of archaeological data (e.g. White 1982). In the light of several lines of more contemporary evidence, this position is no longer tenable.

Firstly, recent and catastrophic origins would imply a small number of mutations, possibly one, and a very sudden spread of the resulting novel alleles. However, such a scenario lacks biological reality, as language is clearly a complex and robust phenomenon unlikely to result from a mysterious evolutionary saltation. It is also difficult to square with the dating of the human diaspora ca. 85 kya and the settlement of Australia ca. 50-60 kya, as any genetic trait postdating this time range would fail to be universally represented in all modern populations (Tallerman 2012: 480).

Clues also come from the design of the human speech production apparatus. This includes the absence of air sacs (conspicuous absence, as air sacs are found in all the other great apes), a descended larynx enabling a "double resonator" configuration of the vocal tract, and an improved innervation of the thorax translating into a high degree of voluntary control over respiration. Although alternative explanations are possible for each of those traits individually, taken together, these costly design modifications are difficult to explain other than as adaptations for articulate speech. Fossil data show essentially modern speech production anatomy by as early as 200 kya, and what appears to be functionally modern anatomy by 400 kya at the least ( $H$. heidelbergensis). The presence of such costly adaptations calls for an explanation, and articulate speech seems no less plausible than a hypothetical articulate but nonlinguistic vocalization system. "Early speech" gains further support from what little genetic evidence we have: the FOXP2 gene, which differs between humans and other apes and plays an important role in both speech production and language more generally, was found to have had the same derived mutations in Neanderthals as in modern humans (Krause et al. 2007).

The archaeological grounding for the "50 kya" inference was in the concept of the so-called "human revolution": a postulated rapid transition to "behavioral modernity" in Homo sapiens populations, characterized by a suite of new phenomena such as advanced technology and art, and reflected in the material culture remains from that period onwards. More recent data, however, point to a much longer and smoother "curve" of cultural-technological progress, with evidence of e.g. decorative ochre use from as early as $300 \mathrm{kya}$, or 
shell beads from 75 kya (see also McBrearty \& Brooks 2000, Watts 2014) ${ }^{20}$. Occasionally, the relatively slow cultural-technological progress in the early anatomically modern $H$. sapiens (between ca. 200-100 kya) is taken as evidence of the absence of language. However, recent studies into cultural evolution suggest that it is mostly population size, rather than the presence of language per se, that is a crucial condition of cumulative cultural development or even maintenance; indeed, a sudden population size reduction may even result in a loss of technological complexity, as was the case in precolonial Tasmania (Henrich 2004).

Consistently with the summary above, an increasing number of authors subscribe to an "early origins" view, and Dediu \& Levinson (2013) express the opinion that a form of communication that humans today would be willing to count as language dates back to at least 500,000 years ago. As we move back in time beyond the 500 kya mark, definitional factors begin to play an increasingly important role. When it comes to protolanguage, authors in the main stream of language evolution research are comfortable putting its origin with $H$. erectus, which may be as far back as 2 million years ago (see e.g. Hewes 1973, Tallerman 2012); needless to say, such estimates are highly speculative and thus put forward merely as the current "best guesses".

\section{Conclusion}

Language has long been considered one of the most important, if not the most important human achievement (Darwin 1871), and its origins continue to be a fascinating puzzle. Even a couple of decades ago this puzzle remained largely a matter of speculation and educated guesses; now, contemporary methodsincluding research into language processing in the brain, ancient DNA genetics, animal communication, semiotic experiments, or "big data" comparative linguistics - offer much better and diverse vantage points, providing new bodies of converging evidence to address old problems. Of these, I single out as the most important the question of the emergence of the honest and cooperative nature of linguistic communication, which I see as the key evolutionary invention en route to modern language.

\footnotetext{
${ }^{20}$ New findings are likely to emerge that are open to interpretation as "artistic”, e.g. "a shell with a geometric engraving” dating back to at least 400 kya (Joordens et al. 2015).
} 


\section{References}

Arbib, M. A. 2005. From monkey-like action recognition to human language: an evolutionary framework for neurolinguistics. Behavioral and Brain Sciences 28: 105-167.

Arbib, M. A. 2013. Précis of How the Brain Got Language: The Mirror System Hypothesis. Language and Cognition 52-3: 107-131.

Axelrod, R. 1984. The Evolution of Cooperation. New York: Basic Books.

Bickerton, D. 1990. Language and species. Chicago: The University of Chicago Press.

Bickerton, D. 1998. Catastrophic Evolution: the case for a single step from protolanguage to full human language. J. Hurford, M. Studdert-Kennedy, C. Knight eds. Approaches to the Evolution of Language. Social and Cognitive Bases. Cambridge, UK: Cambridge University Press: 341-358.

Bickerton, D. 2003. Symbol and structure: a comprehensive framework. M. H. Christiansen, S. Kirby eds. Studies in the Evolution of Language. Oxford University Press: 7793.

Byrne, R. W., Whiten, A. 1988. Machiavellian Intelligence: Social Expertise and the Evolution of Intellect in Monkeys, Apes and Humans. Oxford: Oxford University Press.

Chomsky, N. 2010. Some Simple Evo-devo Theses: How True Might They Be for Language?, in: R. Larson, V. Déprez and H. Yamakido, eds. The Evolution of Human Language. Cambridge: Cambridge University Press, 54-62: 59.

Christiansen, M. H. 1994. Infinite languages, finite minds: Connectionism, learning and linguistic structure. Edinburgh: University of Edinburgh.

Corballis, M. C. 2002. From hand to mouth: The origins of language. Princeton, NJ: Princeton University Press.

Darwin, C. 1871/2011. The Descent of Man and Selection in Relation to Sex. The Project Gutenberg.

Dediu, D., Levinson, S. C. 2013. On the antiquity of language: the reinterpretation of Neandertal linguistic capacities and its consequences. Frontiers in Psychology 4:397, DOI: 10.3389/fpsyg.2013.00397.

Donald, M. 1991. Origins of the modern mind: Three stages in the evolution of culture and cognition. Cambridge: Harvard University Press.

Dor, D. 2014. The instruction of imagination: language and its evolution as a communication technology. In Dor, D., Knight, C., Lewis, J. eds. The social origins of language. Oxford: Oxford University Press: 105-125.

Dunbar, R. 1995. Neocortex size and group size in primates: a test of the hypothesis. Journal of Human Evolution 283: 287-296.

Dunbar, R. 1996. Grooming, gossip and the evolution of language. London: Faber \& Faber.

Dunbar, R. 2007. The social brain hypothesis and its relevance to social psychology. Evolution and the social mind: Evolutionary psychology and social cognition: 21-31. 
Fitch, T. 2010. The Evolution of Language. Cambridge: Cambridge University Press.

Fitch, T., Hauser, M. D., Chomsky, N. 2005. "The evolution of the language faculty: Clarifications and implications. Cognition 97 2: 179-210.

Frisch, von, K. 1957. Erinnerungen eines Biologen. Berlin: Springer.

Frisch, von, K. 1962. Dialects in the language of the bees. Scientific American 207: 7889.

Gentner, T. Q., Fenn, K. M., Margoliash, D., \& Nusbaum, H. C. 2006. Recursive syntactic pattern learning by songbirds. Nature, 4407088, 1204-1207.

Grice, H. P. 1975/1999. Logic and Conversation. A. Jaworski, N. Coupland eds. The Discourse Reader. London: Routledge: 66-77.

Hauser, M. D., Chomsky, N. A., Fitch, T. 2002. The faculty of language: What is it, who has it, and how did it evolve? Science 298: 1569-1579.

Hauser, M. D., Yang, C., Berwick, R. C., Tattersall, I., Ryan, M. J., Watumull, J., .. \& Lewontin, R. C. 2014. The mystery of language evolution. Frontiers in psychology, 5.

Henrich, J. 2004. Demography and cultural evolution: how adaptive cultural processes can produce maladaptive losses: the Tasmanian case. American Antiquity: 197-214.

Hewes, G. W. 1973. Primate communication and the gestural origin of language. Current Anthropology 14.1/2: 5-24.

Hockett, C. F. 1958. A Course in Modern Linguistics. New York: Macmillan.

Hockett, C. F. 1960. The origin of speech. Scientific American 203: 88-111.

Hockett, C. F., Altmann, S. A. 1968. A note on design features. T. Sebeok ed. Animal communication: techniques of study and results of research. Bloomington: Indiana University Press: 61-72.

Jackendoff, R. 1999. Possible stages in the evolution of the language capacity. Trends in Cognitive Sciences 37: 272-279.

Jackendoff, R. 2002. Foundations of Language. Brain, Meaning, Grammar, Evolution. New York: Oxford University Press.

Jackendoff, R., Pinker, S. 2005. The nature of the language faculty and its implications for evolution of language. Cognition 97 2: 211-225.

Jespersen, O. 1922. Language: Its Nature, Development and Origin. London: Allen \& Unwin.

Joordens, J. C., d'Errico, F., Wesselingh, F. P., Munro, S., De Vos, J., Wallinga, J., .. \& Roebroeks, W. 2015. Homo erectus at Trinil on Java used shells for tool production and engraving. Nature, 5187538: 228-231.

Kendon, A. 2011. Some modern considerations for thinking about language evolution: A discussion of the Evolution of Language by Tecumseh Fitch. The Public Journal of Semiotics 31: 79-108. 
Krause, J., Lalueza-Fox, C., Orlando, L., Enard, W., Green, R. E., Burbano, H. A., .. Pääbo, S. 2007. The derived FOXP2 variant of modern humans was shared with Neandertals. Current Biology 1721: 1908-1912.

Leakey, R. 1994. The Origin of Humankind. New York: Perseus Books.

MacNeilage, P. F. 2008. The Origin of Speech. Oxford: Oxford University Press.

Maynard Smith, J. 1982. Evolution and the Theory of Games. Cambridge: Cambridge University Press.

Maynard Smith, J., Harper, D. 2003. Animal Signals. Oxford: Oxford University Press.

McBrearty S. \& Brooks, A. 2000. The revolution that wasn't: a new interpretation of the origin of modern human behaviour. Journal of Human Evolution, 39 5: 453-563.

MacNeilage, P. F. 2008. The Origin of Speech. Oxford: Oxford University Press.

McNeill, D. 2012. How Language Began: Gesture and Speech in Human Evolution. Cambridge: Cambridge University Press

Mithen, S. 2005. The Singing Neanderthals: the origins of music, language, mind and body. London: Weidenfeld and Nicholson.

Parker, A. 2006. Evolving the Narrow Language Faculty: Was Recursion the Pivotal Step? In A. Cangelosi, A. D. M. Smith \& K. Smith Eds., The Evolution of Language: 239246. Singapore: World Scientific Publishing.

Pina, M. Gontier, N. eds. 2014. The Evolution of Social Communication in Primates. A Multidisciplinary Approach. Cham: Springer.

Pinker, S. 1994. The language instinct: How the mind creates languages. New York, HarperCollins.

Power, C. 1998. Old wives' tales: the gossip hypothesis and the reliability of cheap signals. J. R. Hurford, M. Studdert-Kennedy, C. Knight eds. Approaches to the Evolution of Language. Cambridge: Cambridge University Press: 111-129.

Power, C. 2014. Signal evolution and the social brain. D. Dor, C. Knight, J. Lewis eds. The Social Origins of Language. Oxford: Oxford University Press: 47-55.

Savage-Rumbaugh, E. S., Rumbaugh, D. M., Boysen, S. 1980. Do Apes Use Language? One research group considers the evidence for representational ability in apes. American Scientist: 49-61.

Sandler, W. 2013. Vive la différence: Sign language and spoken language in language evolution. Language and Cognition 52-3: 189-203.

Smith, A. 2008. Protolanguage reconstructed. Interaction Studies 91: 100-116.

Tallerman, M. 2012. Protolanguage. K. R. Gibson, M. Tallerman eds. The Oxford Handbook of Language Evolution. Oxford: Oxford University Press: 479-491.

Tomasello, M. 2008. Origins of Human Communication. Cambridge, MA: MIT Press.

Wacewicz, S. 2012. The Narrow Faculty of Language: What Is It, Who Has It, and How Is It Defined? Theoria et Historia Scientiarum 9: 217-229. 
Wacewicz, S., Żywiczyński, P. 2015a. From the narrow to the broad. Multiple perspectives on language evolution. Theoria et Historia Scientiarum 11: 5-18.

Wacewicz, S., Żywiczyński, P. 2015b. Language Evolution: Why Hockett’s Design Features are a Non-Starter. Biosemiotics. DOI: 10.1007/s12304-014-9203-2.

Watts, I. 2014. The red thread: pigment use and the evolution of collective ritual. In Dor, D., Knight, C., Lewis, J. eds. The social origins of language. Oxford: Oxford University Press: 208-227.

White, R. 1982. Rethinking the Middle/Upper Paleolithic transition. Current Anthropology 23: 169-192.

Wray, A. 1998. Protolanguage as a holistic system for social interaction. Language and Communication 18 1: 47-67.

Zahavi, A. 1975. Mate selection - a selection for a handicap. Journal of Theoretical Biology 531: 205-214.

Żywiczyński, P., Wacewicz, S. 2015. Ewolucja języka. W stronę hipotez gesturalnych. Toruń: Wydawnictwo Naukowego Uniwersytetu Mikołaja Kopernika. 